\title{
Analysis of heart rate variability and accelerometry in patients following surgery for the treatment of gastrointestinal cancer
}

Maria Cláudia Valente Almeida1*, Débora Carolina Santos do Nascimento², Laura Maria Tomazi Neves², Juliana Fernandes Dias², Anselmo de Athayde Costa e Silva², Luana Estumano Longhi Bastos ${ }^{3}$, Saul Rassy Carneiro²

\begin{abstract}
Background: Gastrointestinal cancer is the most prevalent form of cancer worldwide. Surgical treatment interferes with functionality and increases the length of hospital stay. However, studies have shown that early mobilization reduces the length of hospital stay. Aim: To determine the cardiovascular safety and intensity of an adapted protocol for early mobilization in patients following surgery for the treatment of gastrointestinal cancer. Methods: An observational, cross-sectional study was conducted with 24 individuals: 15 in the case group (cancer patients in the post-operative period) and nine in the control group (hospitalized patients without cancer). All participants were submitted to a standardized early mobilization physiotherapeutic protocol. A portable heart rate monitor and accelerometer were used to obtain data on heart rate variability (HRV), analyzing the variables 'interval between consecutive beats' (RR), 'mean heart rate' (HR), 'standard deviation from mean of all normal RR intervals' (SDNN), 'square root of mean of square of differences between consecutive RR intervals' (RMSSD), 'number of RR intervals' (NN50) and 'percentage of adjacent RR intervals with difference in duration greater than 50 ms' (pNN50), and the intensity of physical activity (IPA), analyzing metabolic equivalents (METS), before and after the intervention. Data analysis involved the Student's t-test for the comparison of data with parametric distribution and the Mann-Whitney $U$ test for variables with non-parametric distribution. Results: No statistically significant differences in energy expenditure or IPA percentages were found between groups. Moreover, no significant difference in HRV occurred in the case group, whereas differences in RR, HR and pNN50 variables were found in the control group. Conclusions: Early mobilization for patients following surgery for the treatment of gastrointestinal cancer can be performed without increasing HRV and with energy expenditure and IPA similar to those found in patients without cancer.
\end{abstract}

Keywords: Gastrointestinal Neoplasms; Accelerometry; Early Mobilization; Physiotherapy techniques; Heart rate determination.

Universidade do Estado do Pará (UEPA) Belém (PA), Brasil

¿Universidade Federal do Pará (UFPA), Belém (PA), Brasil

${ }^{3}$ Hospital Ophir Loyola (HOL), Belém (PA), Brasil

\section{*Corresponding author:}

Maria Cláudia Valente Almeida

Av. Presidente Vargas, 499

CEP 66017-000, Belém (PA), Brasil

Tel.: +55 (91) 99102-9191

Email: mclaudiavalmeida@gmail.com

Submitted: February 07, 2021

Accepted: December 14, 2021

Study conducted at: Hospital Universitário

João de Barros Barreto (HUJBB), Belém, PA,

Brasil.

Study approved by the Research Ethics

Committee of Hospital Universitário João de

Barros Barreto under opinion n³.416.326.

\section{How to cite}

Almeida MCV, Nascimento DCS, Neves LMT, Dias JF, Silva AAC, Bastos LEL, et al. Analysis of heart rate variability and accelerometry in patients following surgery for the treatment of gastrointestinal cancer. Cardiorespir Physiother Crit Care Rehabil. 2021;1:e42568. https://doi.org/10.4322/2675-9977.cpcr.42568

\section{How can the results of this study be used in clinical practice}

- The results of this study will allow a safer execution of early mobilization by professionals who work in the treatment of this population. 


\section{Introduction}

Cancer of the gastrointestinal tract is the most prevalent form of cancer worldwide and the most common among older adults ${ }^{1}$. The affected organs associated with the highest mortality rates are the stomach, colon, rectum and esophagus $^{2,3}$. Surgical treatment is indicated but can lead to reductions in functionality and the level of physical activity (PA) as well as fatigue and prolonged hospital stay ${ }^{4-6}$.

Several cancer treatments increase cardiovascular risk factors, and chemotherapy has one of the most potentials for cardiotoxicity. Among the adverse effects of chemotherapy, myocardial aggression with systolic ventricular dysfunction and heart failure stand out, leading to ischemia or changes in blood pressure, instability of the pericardial fluid balance, increasing the risk of cardiac arrhythmias. The signals/ symptoms and pathophysiology of cardiotoxicity depend on the type of chemotherapy agent ${ }^{7,8}$.

There is evidence that PA in the pre- and post-cancer treatment periods is safe and associated with improved physical functioning and quality of life as well as a reduction in cancer-related fatigue ${ }^{9,10}$. Moreover, some studies have shown that early mobilization (EM) in the postoperative period following surgery for the treatment of colon cancer reduces the length of hospital stay ${ }^{11}$. Other benefits of EM include an improvement in lung function, the prevention of muscle hypotrophy and orthostatic hypotension, an improvement in the cardiovascular response to exercise, a faster return of adequate intestinal function and a reduced risk of venous thromboembolism ${ }^{11-16}$.

Considering the risks to which patients are exposed in the postoperative period, EM is essential to the recovery of these individuals. However, valid data on cardiovascular safety and the level of intensity of this activity are needed, especially for cancer patients. For such, an accelerometer and heart rate monitor can provide objective data on the intensity of PA, energy expenditure and heart rate variability $(\mathrm{HRV})^{17,18}$.

Therefore, the aim of the present study was to determine the cardiovascular safety and intensity of an adapted EM protocol for patients in the post-operative period following surgery for the treatment of gastrointestinal cancer. Accelerometer and heart rate monitor instruments will be used to achieve the aim of the study.

\section{Methodology}

\section{Design}

An observational, cross-sectional study was conducted at the surgical ward of the João de Barros Barreto University Hospital between June and September 2019. This study received approval from the Human Research Ethics Committee of the hospital (certificate number: 3.416.326) and was conducted in accordance with the research norms involving human subjects stipulated in Resolution 466/12 of the Brazilian National Health Board.

\section{Participants}

The case group consisted of cancer patients from the $1^{\text {st }}$ to the $7^{\text {th }}$ postoperative day following the surgical removal of malignant tumors of the gastrointestinal tract, admitted to the hospital, aged 18 years or older and who agreed to participate in the study by signing a statement of informed consent. The control group consisted of patients admitted to the hospital without a diagnosis of gastrointestinal cancer matched for age and sex to the group of cases and who agreed to participate by signing a statement of informed consent. This choice was based on the definition of nested case and control groups with selection through a predefined cohort. For each case, a control is randomly selected with pairing for the confounding effect of time. The choice of the control is based on the nondiagnosis of the disease in question, but control subjects may have other adverse health conditions and the group does not necessarily need to be composed of healthy individuals ${ }^{19}$. The exclusion criteria were an inability to start or end the protocol and having other limiting conditions that would interfere with data collection, such as respiratory failure, uncontrolled cardiovascular disease, unstable angina, severe systemic diseases recent embolism, uncontrolled diabetes or orthopedic conditions that would limit the application of the mobilization protocol.

\section{Instruments}

\section{Accelerometer}

The Actigraph GT3X tri-axial device was used. This tool calculates energy expenditure and time spent on activities of different intensities. It also enables the determination of the sum of vector magnitude movements along three axes and has proved reliable for measuring the level of PA in adults during activities of daily living ${ }^{20-22}$.

\section{Heart rate monitor}

The portable Polar® S810 (Polar Electro, Kempele, Finland) was used, which has a sampling frequency of 1000 $\mathrm{Hz}^{23,24}$. This equipment has been validated to capture the beat-by-beat heart rate for the analysis of HRV.

\section{Evaluation form}

A form was used for the collection of the following data: name, age, sex, type of cancer, type of surgery, place of surgery, other diseases (arterial hypertension, diabetes, allergies, infections, etc.) and vital signs as well as the scores on the modified Borg scale, visual analog pain scale and Karnofsky Performance Status (KPS) scale. The KPS scale ranges from 0 to 100 , with higher scores denoting less impairment due to disease ${ }^{25,26}$. Evaluation was performed by two different individuals. 


\section{Free and informed consent}

The term was initially composed of project information, main objectives, followed by risks and benefits and finally the patient's signature. Regarding the risks, it was included the possible breach of confidentiality, possible side effects of the physical exercise protocol, and inconvenience during the evaluation process; the researchers were held fully responsible, and whatever was necessary was done to alleviate the situation. The benefits of the research included an increase in the scientific community, through articles and works published in the media, knowledge about the evidence of the executed protocol and the instruments used, thus expanding the theoretical framework of the area involved. Above all, it would bring benefits to cancer patients receiving physical therapy treatment.

\section{Intervention}

Data collection was performed in a single one-hour session. Vital signs were measured at three different timepoints: 20 minutes before, during and 20 minutes after the protocol. The accelerometer and heart rate monitor were used continuously throughout the data collection period. The physiotherapeutic protocol was adapted from Morris et al. ${ }^{27}$. A cycle ergometer was used for five minutes for the lower limbs and upper limbs, followed by elbow flexion, elbow extension and horizontal shoulder abduction performed in two sets of 10 repetitions with light elastic band resistance. Both the case and control groups underwent the same protocol.

\section{Statistical analysis}

Data analysis involved the Student's t-test for the comparison of data with parametric distribution and the Mann-Whitney U test for variables with non-parametric distribution. The level of significance was set to $5 \%(\mathrm{p}<0.05)$ for the rejection of the null hypothesis.

\section{Results}

A total of 24 individuals were included in the study: 15 in the case group (patients in the postoperative period after surgery for the treatment of gastrointestinal cancer) and nine in the control group (hospitalized patients without cancer). Table 1 displays the demographic and clinical characteristics of the groups.

Table 2 shows the mean energy expenditure in METS and median percentage of intensity during the intervention. No statistically significant differences were found for these variables between the two groups.

Table 3 displays the variables related to HRV in the time domain before and after the intervention. No significant difference in HRV occurred in the case group, whereas differences in RR, HR and pNN50 variables were found in the control group.
Table 1. Demographic and clinical characteristics of case and control groups.

\begin{tabular}{lcc}
\hline \multicolumn{1}{c}{ Characteristics } & Case & Control \\
\cline { 2 - 3 } Sex & $(\mathbf{n}=\mathbf{1 5})$ & $(\mathbf{n}=\mathbf{9})$ \\
Female & & \\
Male & $7(46.6 \%)$ & $3(33.3 \%)$ \\
Age (mean and & $8(53.3 \%)$ & $6(66.6 \%)$ \\
standard deviation) & $53.2 \pm 14.8$ & $55.4 \pm 10.2$ \\
Type of cancer & & Inpatient Diagnosis \\
Gastric & $6(40 \%)$ & Umbilical hernia $(\mathrm{n}=3 ;$ \\
Pancreatic & & $33.3 \%)$ \\
Hepatic & $2(13.3 \%)$ & Gallstones (n=3; $33.3 \%)$ \\
Intestinal & $1(6.6 \%)$ & Hepatic cirrhosis (n=1; \\
& & $11.1 \%)$ \\
Rectal & $2(13.3 \%)$ & Thoracic Trauma (n=1; \\
KPS & & $11.1 \%)$ \\
\hline
\end{tabular}

KPS (median and interquartile range [IIQ])

Table 2. METS and percentages of PA intensity in case and control groups.

\begin{tabular}{lccc}
\hline \multirow{2}{*}{ Variables } & Case & Control & p-value \\
\cline { 2 - 3 } & $(\mathbf{n}=\mathbf{1 5})$ & $(\mathbf{n}=\mathbf{9})$ & \\
\hline METS & $1317.3 \pm$ & $1479.4 \pm$ & NS \\
\% Inactivity & 386.9 & 594.3 & \\
\% Light & 50 & 40 & NS \\
\% Moderate & 40 & 45 & NS \\
\% Vigorous & 14 & 13 & NS \\
\hline
\end{tabular}

METS: metabolic equivalent of task (mean and standard deviation); Intensity percentages (median); NS: non-significant.

\section{Discussion}

The present study investigated HRV and PA level in patients hospitalized in the postoperative period of gastrointestinal cancer in view of the scarcity of published articles addressing this topic. No significant changes in HRV were found after the exercise protocol compared to the preintervention period. Moreover, no significant differences were found in the percentage of physical inactivity, light, moderate or vigorous exercise between groups. Therefore, the proposed protocol is safe for this population. ThraenBorowski et al. ${ }^{10}$ suggest that PA is safe during and after cancer treatment and can lead to improvements in physical functioning and quality of life as well as a reduction in fatigue in certain types of cancer. 
Table 3. Variables related to heart rate variability in case and control groups (intragroup evaluation).

\begin{tabular}{|c|c|c|c|c|c|c|}
\hline \multirow{3}{*}{ Variables } & \multicolumn{2}{|c|}{ Case } & \multirow{3}{*}{ p-value } & \multicolumn{2}{|c|}{ Control } & \multirow{3}{*}{ p-value } \\
\hline & \multicolumn{2}{|c|}{$(n=15)$} & & \multicolumn{2}{|c|}{$(n=9)$} & \\
\hline & \multicolumn{2}{|c|}{ Before After } & & \multicolumn{2}{|c|}{ Before After } & \\
\hline $\mathbf{R} \mathbf{R}$ & $801.3 \pm 151.2$ & $677.5 \pm 110.5$ & NS & $780.1 \pm 103.2$ & $656.6 \pm 93.5$ & $<0.05$ \\
\hline HR & $77.4 \pm 15.9$ & $90.5 \pm 13.6$ & NS & $78.1 \pm 9.7$ & $93.2 \pm 13.6$ & $<0.05$ \\
\hline SDNN & $344.4 \pm 536.7$ & $134.5 \pm 98.5$ & NS & $380.7 \pm 481.4$ & $172.7 \pm 112$ & NS \\
\hline RMSSD & $452 \pm 721.8$ & $181 \pm 140.2$ & NS & $472.9 \pm 623.3$ & $217.2 \pm 142.7$ & NS \\
\hline NN50 & $61.1 \pm 78.4$ & $75.5 \pm 88.2$ & NS & $28.5 \pm 28.4$ & $61.8 \pm 63.3$ & NS \\
\hline pNN50 & $35.6 \pm 32.4$ & $44.6 \pm 34.7$ & NS & $30.5 \pm 23.1$ & $19.8 \pm 17.7$ & $<0.05$ \\
\hline
\end{tabular}

Student's t-test significant alpha level.RR: interval between consecutive beats; HR: mean heart rate; SDNN: standard deviation from mean of all normal RR intervals; RMSSD: square root of mean of square of differences between consecutive RR intervals; NN50: number of RR intervals; pNN50: percentage of adjacent RR intervals with difference in duration greater than $50 \mathrm{~ms}$; NS: non-significant.

The American Cancer Society recommends at least 150 minutes per week of moderate aerobic and strengthening exercises for cancer patients ${ }^{28}$. However, it is necessary to start training with less intensity and duration, followed by a gradual intensification based on the patient's functional capacity and comorbidity status ${ }^{29}$. The measurement of PA is relevant to assessing the effectiveness of interventions to increase PA levels in cancer patients. According to Broderick et al. ${ }^{30}$, there is no consensus regarding the minimum number of valid monitoring days; the period should not be too uncomfortable for the patient but should be long enough to portray the usual level of activity.

Cancer patients have a greater tendency towards immobilization due to pain, fatigue and psychological weakness, leading to restrictions to exercise. In the hospital setting, there are even more restrictions to PA due to the limited space as well as the patients' lack of recognition regarding the benefits of exercise. Thus, counseling by the healthcare team is necessary to make individuals aware of the advantages of staying active in the hospital ${ }^{11,32}$.

Heart rate can be used to measure daily energy expenditure due to the linear relation between these variables over a wide range of activity levels. Chemotherapy can increase HRV due to its effect on autonomic function ${ }^{30}$. SDNN is a variable that reflects general sympathetic and vagal activity, while RMSSD mainly reflects sympathetic activity. In the present study, reductions in SDNN and RMSSD were found in the cancer patients before and after physical exercise. Indeed, patients in the postoperative period often exhibit changes in sympathetic-vagal balance, decreased HRV and sympathetic hyperactivity due to surgical stress, which can last through the first month after surgery ${ }^{33}$.

Mostarda et al. ${ }^{34}$ investigated the effects of short-term physical training on cardiorespiratory fitness and autonomic modulation in women with breast cancer undergoing adjuvant therapy. The exercises performed at the hospital consisted of aerobic, resistance and flexibility training performed at a frequency of three times a week on non-consecutive days for four weeks. The authors found that women with breast cancer had autonomic dysfunction and less tolerance to exercise compared to the control group. SDNN, RMSSD and RR values were lower in the cancer group after the protocol. However, this situation had changed after one month of intervention, as demonstrated by the similar results on the cardiorespiratory test and HRV between groups. A similar population was evaluated in another study with an eight-week intervention, in which an increase in SDNN and RMSSD was found in the experimental group compared to the control group (no intervention), demonstrating that exercise increases the general activity of the autonomic nervous system ${ }^{35}$.

The present findings reveal that despite the lower functionality compared to the control group, cancer patients were able to perform physical exercises with energy expenditure equivalent to that of the other patients, demonstrating that the diagnosis itself did not interfere decisively with this variable. Moreover, there was no significant change in HRV. One study reported reductions in muscle strength and functional capacity in the postoperative period, when recovery depends on several factors. The reduction of surgical stress, enteral nutrition and early mobilization are important interventions that improve fatigue and functionality. The aim of patient mobilization on the first postoperative day following upper gastrointestinal resection is the acceleration of physical functioning and a reduction in the occurrence of postoperative and pulmonary complications. Indeed, remaining bedridden for long periods is known to exert a negative impact on physical aspects ${ }^{5}$.

The scientific evidence on this topic is limited, but researchers agree that the population with neoplasia tends to be more inactive compared to the healthy population, which underscores the importance of interventions designed to promote patient mobilization during hospitalization to improve PA levels ${ }^{36}$. The present findings demonstrate that the proposed protocol is safe from the cardiovascular standpoint and physical therapy should be strongly encouraged for these individuals 
This study had some limitations that need to be considered. There were not enough patients in the control group to match the cases according to the age and sex criteria, which explains the difference in the sample size of the two groups. Moreover, administrative problems occurred at the hospital during the study period, resulting in the non-admission of new patients and a reduction in the number of surgeries, which had a negative impact on the sample size.

\section{Conclusion}

The present results demonstrate that early mobilization does not increase HRV and can be safely performed in patients in the postoperative period following surgery for gastrointestinal cancer treatment. Moreover, no statistically significant differences were found in energy expenditure or PA intensity between the cases and controls during the protocol, despite the lower level of functionality in patients who composed the case group. It is hoped that this work can pave the way for further research addressing early physical activity in patients hospitalized for cancer treatment.

\section{Funding}

There is no funding for this study. Data available upon request. The authors have no conflicts of interest to declare.

\section{Conflict of interest}

None.

\section{References}

1. Xue DD, Cheng Y, Wu M, Zhang Y. Comprehensive geriatric assessment prediction of postoperative complications in gastrointestinal cancer patients: a meta-analysis. Clin Interv Aging. 13:723-36. http:// dx.doi.org/10.2147/CIA.S155409.

2. Zhang L, Song X, Li X, Wu C, Jiang J. Yes-associated protein 1 as a novel prognostic biomarker for gastrointestinal cancer: a meta-analysis. BioMed Res Int. 2018:4039173. http://dx.doi. org/10.1155/2018/4039173.

3. De GN, Olmos M, Calleja A, Campos C, Pérez A, Cruz D, et al. Nutrición Hospitalaria Trabajo Original. Nutr Hosp. 2019;34(1):15-8.

4. Lee TG, Kang SB, Kim DW, Hong S, Heo SC, Park KJ. Comparison of early mobilization and diet rehabilitation program with conventional care after laparoscopic colon surgery: a prospective randomized controlled trial. Dis Colon Rectum. 2011 Jan;54(1):21-8. http://dx.doi. org/10.1007/DCR.0b013e3181fcdb3e. PMid:21160309.

5. Carvalho JB, Salgado NA, Silva ACM, Ramos EMLS, Demachki S, Araujo MS. Fatores de risco socioambientais e nutricionais envolvidos na carcinogênese gástrica. Rev. para. med = Rev. Para. Med. (Impr.). [Internet]. 2011 [cited 2019 July 26];25(2/3):1-9. Avaliable from: http://bases.bireme.br/cgi-bin/ wxislind.exe/iah/online/ ?IsisScript=iah/ iah. $x$ is \& src $=$ google \&base $=$ LILACS\&lang $=$ p\&nextAction $=$ lnk\&exprSearch $=621063 \&$ indexSearch $=$ ID

6. Vermillion SA, James A, Dorrell RD, Brubaker P, Mihalko SL, Hill AR, et al. Preoperative exercise therapy for gastrointestinal cancer patients: a systematic review. Syst Rev. 2018 Jul 24;7(1):103. http:// dx.doi.org/10.1186/s13643-018-0771-0. PMid:30041694.

7. Adão R, De Keulenaer G, Leite-Moreira A, Brás-Silva C. Cardiotoxicidade associada à terapêutica oncológica: mecanismos fisiopatológicos e estratégias de prevenção. Rev Port Cardiol. 32(5):395-409. http://dx.doi.org/10.1016/j.repc.2012.11.002.

8. Kalil R Fo, Hajjar LA, Bacal F, Hoff PM, Diz MP, Galas FRBG. I Diretriz Brasileira de Cardio-Oncologia da Sociedade Brasileira de Cardiologia. Arq Bras Cardiol. 2011;96(2 Suppl 1):1-52. http://dx.doi. org/10.1590/S0066-782X2011000700001. PMid:21468528.

9. Onerup A, Angenete E, Bock D, Börjesson M, Fagevik Olsén M, Grybäck Gillheimer E, et al. The effect of pre- and post-operative physical activity on recovery after colorectal cancer surgery (PHYSSURG-C): study protocol for a randomised controlled trial. Trials. 2017 May 8;18(1):212. http://dx.doi.org/10.1186/s13063-0171949-9. PMid:28482864.

10. Thraen-Borowski KM, Gennuso KP, Cadmus-Bertram L. Accelerometer-derived physical activity and sedentary time by cancer type in the United States. PLoS One. 2017 Aug 14;12(8):e0182554. http://dx.doi.org/10.1371/journal.pone.0182554. PMid:28806753.

11. van Der Leeden M, Huijsmans R, Geleijn E, De Lange-De Klerk ES, Dekker J, Bonjer HJ, et al. Early enforced mobilisation following surgery for gastrointestinal cancer: feasibility and outcomes. Physiotherapy. 2016 Mar;102(1):103-10. http://dx.doi.org/10.1016/j. physio.2015.03.3722. PMid:26059985.

12. avey R, Herriman E, O'Brien D. Guarding the gut: early mobility after abdominal surgery. Crit Care Nurs Q. 2013 Jan-Mar;36(1):63-72. http:// dx.doi.org/10.1097/CNQ.0b013e3182753237. PMid:23221443.

13. Cassidy M, Rosenkranz P, McAneny D. Reducing postoperative venous thromboembolism complications with a standardized risk-stratified prophylaxis protocol and mobilization program. Am Coll Surg. 218(6):1095-104. http://dx.doi.org/10.1016/j.jamcollsurg.2013.12.061.

14. Rocha ARM, Martinez BP, Silva VZM, Forgiarini LA Jr. Early mobilization: why, what for and how? Med Intensiva. 2017 Oct;41(7):429-36. http://dx.doi.org/10.1016/j.medin.2016.10.003. PMid:28283324.

15. Hanada M, Kanetaka K, Hidaka S, Taniguchi K, Oikawa M, Sato $\mathrm{S}$, et al. Effect of early mobilization on postoperative pulmonary complications in patients undergoing video-assisted thoracoscopic surgery on the esophagus. Esophagus. 15(2):69-74. https://doi. org/10.1007/s10388-017-0600-x.

16. Hussey JM, Yang T, Dowds J, O’Connor L, Reynolds JV, Guinan EM. Quantifying postoperative mobilisation following oesophagectomy. Physiotherapy. 2019 Mar;105(1):126-33. http://dx.doi.org/10.1016/j. physio.2018.08.004. PMid:30343873.

17. Lopes PFF, Oliveira MIB, André SMS, Nascimento DLA, Silva CSS, Rebouças GM, et al. Aplicabilidade Clínica da Variabilidade da Frequência Cardíaca. Revista Neurociências. 2013;21(4):600-3. http:// dx.doi.org/10.34024/rnc.2013.v21.8171.

18. Sasaki J, Coutinho A, Santos C, Bertuol C, Minatto G, Berria J, et al. Orientações para utilização de acelerômetros no Brasil. Rev Bras Ativ Fís Saúde. 2017;22(2):110-26. https://doi.org/10.12820/ rbafs.v.22n2p110-126.

19. Rêgo MAV. Estudos caso-controle: uma breve revisão. GMBahia. [Internet]. 2010 [cited 2019 Aug 1];80:101-10. Avaliable from: http:// www.gmbahia.ufba.br/index.php/gmbahia/article/view/1089

20. Aadland E, Ylvisåker E. Reliability of the actigraph GT3X+ accelerometer in adults under free-living conditions. PLoS One. 2015 Aug 14;10(8):e0134606. http://dx.doi.org/10.1371/journal. pone.0134606. PMid:26274586.

21. Feehan LM, Goldsmith CH, Leung AY, Li LC. SenseWearMini and actigraph GT3X accelerometer classification of observed sedentary and light-intensity physical activities in a laboratory setting. Physiother Can. 2016;68(2):116-23. http://dx.doi.org/10.3138/ptc.2015-12. PMid:27909358.

22. Gastin PB, Cayzer C, Dwyer D, Robertson S. Validity of the ActiGraph GT3X+ and BodyMedia SenseWear Armband to estimate energy 
expenditure during physical activity and sport. J Sci Med Sport. 2018 Mar;21(3):291-5. http://dx.doi.org/10.1016/j.jsams.2017.07.022. PMid:28797831.

23. Vanderlei FM, Rossi RC, Souza NM, Sá DA, Gonçalves TM, Pastre $\mathrm{CM}$ et al. Heart rate variability in healthy adolescents at rest. Rev Bras Crescimento Desenvolv Hum. [Internet]. 2012 [cited 2019 July 26];22(2):173-8. Available from: http://pepsic.bvsalud.org/scielo. php?script $=$ sci_arttext\&pid=S0104-12822012000200008

24. Reis HV, Borghi-Silva A, Catai AM, Reis MS. Impact of CPAP on physical exercise tolerance and sympathetic-vagal balance in patients with chronic heart failure. Braz J Phys Ther. 2014;18(3):218-27. http:// dx.doi.org/10.1590/bjpt-rbf.2014.0037. PMid:25003274.

25. Khalid MA, Achakzai IK, Ahmed Khan S, Majid Z, Hanif FM, Iqbal $\mathrm{J}$, et al. The use of Karnofsky Performance Status (KPS) as a predictor of 3 month post discharge mortality in cirrhotic patients. Gastroenterol Hepatol Bed Bench. 2018;11(4):301-5. PMid:30425808.

26. Thuluvath PJ, Thuluvath AJ, Savva Y. Karnofsky performance status before and after liver transplantation predicts graft and patient survival. J Hepatol. 2018 Oct;69(4):818-25. http://dx.doi.org/10.1016/j. jhep.2018.05.025. PMid:29883596.

27. Morris PE, Goad A, Thompson C, Taylor K, Harry B, Passmore L, et al. Early intensive care unit mobility therapy in the treatment of acute respiratory failure. Crit Care Med. 2008 Aug;36(8):2238-43. http:// dx.doi.org/10.1097/CCM.0b013e318180b90e. PMid:18596631.

28. Demark-Wahnefried W, Rogers LQ, Alfano CM, Thomson CA, Courneya KS, Meyerhardt JA, et al. Practical clinical interventions for diet, physical activity, and weight control in cancer survivors. CA Cancer J Clin. 2015 May-Jun;65(3):167-89. http://dx.doi.org/10.3322/ caac.21265. PMid:25683894.

29. Oruç Z, Kaplan MA. Effect of exercise on colorectal cancer prevention and treatment. World J Gastrointest Oncol. 2019 May 15;11(5):348-66. http://dx.doi.org/10.4251/wjgo.v11.i5.348. PMid:31139306.
30. Broderick JM, Ryan J, O’Donnell DM, Hussey J. A guide to assessing physical activity using accelerometry in cancer patients. Support Care Cancer. 22(4):1121-30. https://doi.org/10.1007/s00520-013-2102-2.

31. Chang IY, Yi ES. The influence of environmental constraints within hospitals on physical activity level of cancer patients. J Exerc Rehabil. 2018 Jun 30;14(3):382-6. http://dx.doi.org/10.12965/jer.1836240.120. PMid:30018922.

32. Kim JY, Jeon SW, Yi ES. A study of the physical activity restriction in the cancer patients using hierarchical regression analysis. J Exerc Rehabil. 2018 Oct 31;14(5):835-43. http://dx.doi.org/10.12965/ jer.1836380.190. PMid:30443531.

33. Dericioglu N, Demirci M, Cataltepe O, Akalan N, Saygi S. Heart rate variability remains reduced and sympathetic tone elevated after temporal lobe epilepsy surgery. Seizure. 2013 Nov;22(9):713-8. http:// dx.doi.org/10.1016/j.seizure.2013.05.007. PMid:23746623.

34. Mostarda C, Castro-Filha J, Reis AD, Sevílio M Jr, Dias CJ, SilvaFilho AC, et al. Short-term combined exercise training improves cardiorespiratory fitness and autonomic modulation in cancer patients receiving adjuvant therapy. J Exerc Rehabil. 2017 Oct 30;13(5):599607. http://dx.doi.org/10.12965/jer.1735048.524. PMid:29114536.

35. Shin HC, Yang JO, Kim SR. Effects of circuit exercise on autonomic nerve system of survivors after surgery of breast cancer. J Phys Ther Sci. 2016 Oct;28(10):2898-903. http://dx.doi.org/10.1589/jpts.28.2898. PMid:27821958.

36. McDonald L, Oguz M, Carroll R, Thakkar P, Yang F, Dhalwani $\mathrm{N}$, et al. Comparison of accelerometer-derived physical activity levels between individuals with and without cancer: a UK Biobank study. Future Oncol. 2019 Nov;15(33):3763-74. http://dx.doi.org/10.2217/ fon-2019-0443. PMid:31637942. 


\section{Author contributions}

MCVA: Conceptualization of the study; Funding acquisition; Writing, revising and/or editing the manuscript; DCSN: Conceptualization of the study; Funding acquisition; Writing, revising and/or editing the manuscript; LMTN: supervision, analysis and/or interpretation; JFD: supervision, analysis and/or interpretation; AACS: supervision, analysis and/or interpretation; LELB: analysis and/or interpretation and revising and/or editing the manuscript; SRC: Conceptualization of the study; Data acquisition, supervision, analysis and/or interpretation; revising and/or editing the manuscript.

\section{Author information}

MARIA CLÁUDIA VALENTE ALMEIDA

Graduated in Physiotherapy, Universidade Federal do Pará, Brazil

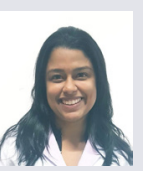

\section{DÉBORA CAROLINA SANTOS DO NASCIMENTO}

Graduated in Physiotherapy, Universidade Federal do Pará, Brazil

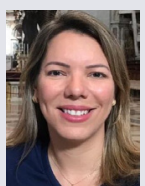

\section{AURA MARIA TOMAZI NEVES}

Graduated in Physiotherapy, Universidade do Estado do Pará, Brazil Specialization in cardiovascular physiotherapy from UNIFESP, Brazil

Master's in Physiotherapy at UFSCar

Doctorate in Health Sciences and Technologies at UnB

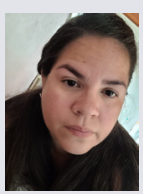

\section{JULIANA FERNANDES DIAS}

Graduated in Physiotherapy, Centro Universitário do Pará, Brazil

Postgraduate in pediatrics and neonatology from Universidade Federal de São Paulo, Brazil

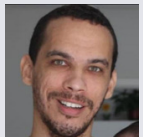

\section{ANSELMO DE ATHAYDE COSTA E SILVA}

Graduated in Physical Education, Universidade Paranaese, Brazil

Doctorate in adapted physical activity from UNICAMP

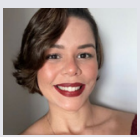

\section{LUANA ESTUMANO LONGHI BASTOS}

Graduated in Physiotherapy, Universidade da Amazônia, Belém, Pará, Brazil Postgraduate in Musculoskeletal Physiotherapy from the Brotherhood of Santa

Casa de Misericórdia de São Paulo and in Physiotherapy in Intensive Care from the Universidade da Amazônia

Physiotherapist of Division of Hematology, Hospital Ophir Loyola, Pará, Brazil

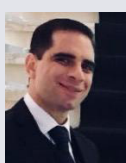

\section{SAUL RASSY CARNEIRO}

Doctorate in Tropical Diseases from the Federal University of Pará

Physiotherapist at the Hospital Universitário João de Barros Barreto and from the Special Public Health Secretariat of the State of Pará

Administrative technician at the Federal University of Pará. Belém, Pará, Brazil 